\title{
A PARAMETRIC STUDY ON CABLE-STAYED BRIDGES BY THE LIMIT STATES DESIGN
}

\author{
By Shunichi NAKAMURA* and T.A. WYATT**
}

\begin{abstract}
Cable-stayed bridges with multi-stays have been recently planned and constructed in many countries probably because of aesthetic and economical superiority. It would be generally possible that the girder could become much slender by properly controlled cable prestresses. The system has been designed in this paper by mainly BS 5400 , one of the few codes which have introduced the limit states design. The consistently optimised designs have been achieved by Linear Programming in order to compare the various bridge configuration. A simple method has been proposed to estimate the buckling capacity of the girder. The girder stiffness obtained is substantially lower than that of existing bridges. The bridge with multi-cables could have much slender girders than that with few-cables.

Keywords: cable-stayed bridges, limit states design, optimisation, cable prestress
\end{abstract}

\section{INTRODUCTION}

The multi-stay bridges have several advantages such as slender girders, compact anchorages of cables, small size cables and easy replacement of cables. The system has also a favorable dynamic property, which is the system damping effect. Each of many inclined cables with the mass of the deck belonging to it would have a different resonant frequency, therefore, the development of resonance is likely to be interrupted. Another feature of cable-stayed bridges is that the bending moments of the girder can be controlled by cable prestressing to induce a predetermined distribution of moments on the dead load configuration. The systematic way to determine prestress forces has been developed and explained in this paper.

The limit states design has already been introduced in U. K. and U. S. A. . It has been reported that the steel bridges could be more economically designed by this method ${ }^{12}$. Autostress method ${ }^{2}$, which uses the compact rolled H-sećtion, is one of the good examples to show the effectiveness of the limit states design. Japan is currently carrying out a wide study on load factors and ultimate strength of members to establish a design code. A trial has already been made to apply the load factor design to the Akashi Bridge ${ }^{3)}$.

Cable-stayed bridges with different spans and number of cables have been designed using the limit states design so that they could have consistently optimised girder stiffness. Load factors and nominal live loads in BS $5400^{4)}$ have been used in this paper, which would be useful to introduce the British way to design. Although a couple of studies to determine optimum cable prestresses ${ }^{5)-7)}$ have already been proposed, one based on the limit states design has not studied before.

* Member of JSCE, Ph. D. , Bridge Engineering and Construction Div., Nippon Steel Corp. (2-6-3 Otemachi, Chiyoda-ku, Tokyo 100)

** Ph. D., Dept. of Civil Engineering, Imperial College. (London SW 7, U. K.) 


\section{LIMIT STATES DESIGN}

The basic equation of the limit states is

$S<R$

where, $S$ is loads and $R$ resistance. Then $R$ and $S$ are expressed by $F_{k}:$ nominal strength of materials, $K_{m}$ : material reduction factor, $K_{f 3}$ : factor that takes account of inaccurate assessment of defect of loading and unforseen stress distribution accompanied by analysis and construction, $K_{f 1}:$ partial load factor and $Q_{k}$ : nominal loads.

$$
\begin{aligned}
& R=F_{k} / K_{m} \\
& S=K_{f_{3}} K_{f_{1}} Q_{k}
\end{aligned}
$$

where, for the ultimate limit state of steel structures, BS 5400 specifies:

$$
\begin{aligned}
K_{f 3} & =1.1 \\
K_{f_{1}} & = \begin{cases}1.05 & \text { for steel } \\
1.15 & \text { for concrete } \\
1.5 & \text { for live loads }\end{cases}
\end{aligned}
$$

Applying the above equations to the cable design, we have

$$
T[1.1(1.05 D+1.5 L)]<k_{c} T_{u}
$$

where $T:$ cable tension function, $D:$ dead loads (mainly steel), $L:$ live loads, and $T_{u}:$ ultimate strength of a cable.

It is far from easy to find the value $k_{c}$ because there is not a clear yield stress in cables unlike steel plates. $0.2 \%$ off-set strength (residual strain is $0.2 \%$ ) would be a reasonable value to take as a nominal strength of a strand. This value for spiral strands generally ranges 0.6 to 0.75 of the ultimate strength depending on the strand diametres. If you take the material reduction factor $K_{m}$ of 1.2 , the resistance $R$ averages $(0.6$ to 0.7$) / 1.2 \fallingdotseq 0.6 T_{u}$. This is the value chosen in this paper. On the other hand, DIN 1073 is based on the working stress method (allowable stress method). We can write the design method of DIN in a similar way,

$$
T[D+L]<0.42 T_{u}
$$

If you compare eq. ( 3 ) and eq. ( 4 ), it is clear that both equations are same when $L / D=1$. 23. When $L / D$ is smaller than 1.23 , eq. ( 3 ) can be more effective. Resistant cable tension can be increased by about $2 \%$, $8 \%$ and $15 \%$ when $L$ is $D, 0.5 D$ and $0.2 D$ respectively.

HA loads of BS 5400 has been used as design live loads. The concentrated live load $w_{c}$ is $120 \mathrm{kN}$ per notional lane. The distributed live load $w_{1}$ is $30 \mathrm{kN} / \mathrm{m}$ for loaded length up to $30 \mathrm{~m}$ per notional lane, and for loaded length over $30 \mathrm{~m}$ eq. ( 5 ) is applied.

$$
w_{1}=151\left(1 / L_{0}\right)^{0.475} \text { but not less than } 9 \mathrm{kN} / \mathrm{m} \text {. }
$$

where, $L_{0}$ is the loaded length which is the length between two zero points on the influence line. The influence line of bending moments has quite sharp peaks and this tendency becomes stronger for the system with more stays.

\section{OPTIMISATION METHOD}

The stress due to bending moments and axial forces caused by factored loads should satisfy the following stress equations, eq. (6) to eq. (8), at the bottom and upper flanges on every point of the girder. The simplified trapezoidal cross section with stiffened plates, as shown in Fig. 1, is assumed in this study. The torsional rigidity of this section is considerably large and the effect of lateral torsional buckling is small.

$$
\begin{aligned}
& \frac{M_{k}^{-}-m_{k}}{z_{1} \sigma_{1 c} / r_{2}}+\frac{N_{k}}{A_{g} \sigma_{c} / r_{1}}>-1 \\
& \frac{M_{k}^{+}+m_{k}}{z_{1} \sigma_{1 c} / r_{2}}+\frac{N_{k}}{A_{g} \sigma_{y} / r_{1}}<1 \cdots
\end{aligned}
$$


$\frac{-M_{k}^{+}-m_{k}}{z_{u} \sigma_{1 c} / r_{2}}+\frac{N_{k}}{A_{g} \sigma_{c} / r_{1}}>-1$

where, $M_{k}^{+}, M_{k}^{-}$: maximum and minimum bending moment at position $k$ on the girder, $N_{k}$ : axial force at $k$ (plus for tension and minus for compression), $z_{u}, z_{1}$ : section modulus of upper and lower flange, $A_{g}$ : cross sectional area of the girder, $\sigma_{y}$ : yield stress, $\sigma_{c}$ : least ultimate stress for buckling, $\sigma_{1 c}$ : limiting compressive stress from Fig. 3.10 in part 3, BS 5400 , and $m_{k}$ : additional moment due to shear lag effect which has been explained in 4. $r_{1}=K_{m} K_{f 3}=1.155$ and $r_{2}=1.32$.

Fig. 2 shows the stress distribution at the top and bottom flange due to sagging and hogging bending moments as well as compressive axial forces. The stress equations, eq. ( 6 ) to eq. ( 8 ), correspond to the bottom flange stress due to hogging moment, the bottom flange stress due to sagging moment, and the upper flange stress due to sagging moment respectively. The upper flange stress due to hogging moment is less critical than eq. ( 7 ) because the neutral axis is usually closer to the upper flange and axial forces are always compressive.

Cable tensions due to factored dead loads, live loads and prestresses should not be slacked nor the tension be over the upper allowable.

$T_{k}^{-}>k_{1} T_{u}$

$T_{k}^{+}<k_{u} T_{u}$

where, $T_{k}^{-}, T_{k}^{+}$: minimum and maximum cable tensions of cable $i$, and $k_{1}, k_{u}$ : lower and upper limits of cable tensions $\left(k_{1}=0.1\right.$ and $k_{u}=0.6$ are assumed).

The compressive axial force and hogging moment are usually maximum at the tower, therefore; the moment at that point is minimised in the first place under the constraints of eq. (6) to eq. (10). At this stage the girder is assumed to be uniform along the span, and $z_{1}$ and $z_{u}$ are the same at all point on the girder.

$-M_{t}^{-} \rightarrow$ to be minimised

The optimum method with this objective function usually produces a combination of bending moments and axial forces which gives a uniform girder stiffness over the whole span and can be considered as the optimum solution in a practical sense. However, there are some cases in which the sagging moments at the centre or near the abutment can be improved, especially when the side span is much shorter or longer than the usual cases. In those situation, after the first optimisation, the moment at the tower is fixed and the sagging moment to be reduced $M_{j}^{+}$is taken as the second objective function.

$M_{j}^{+} \rightarrow$ to be minimised.

Introducing prestress forces $P_{i}$ for each cable $i$, the maximum and minimum bending moments $M_{k}^{+}$and $M_{\bar{k}}^{-}$at each position are expressed :

$$
M_{\kappa}^{+}=w_{d} A_{k}+w_{1} A_{\kappa}^{+}+w_{c} b_{k}^{+}+\sum_{i} P_{i} f_{i, k}
$$

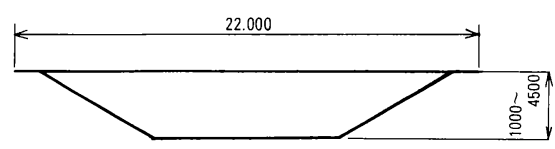

Fig. 1 Girder cross section.
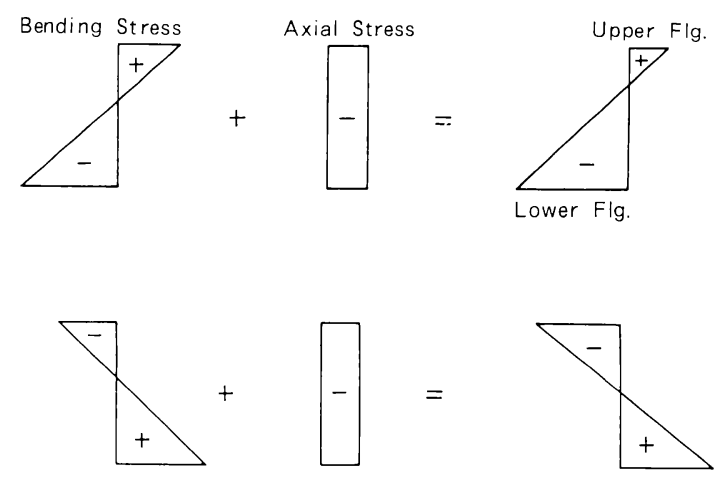

Fig. 2 Stress states of the girder. 


$$
M_{\bar{k}}^{-}=w_{d} A_{k}+w_{1} A_{\bar{k}}^{-}+w_{c} b_{\bar{k}}^{-}+\sum_{i} P_{i} f_{i, k}
$$

where, $f_{i, k}$ : bending moments at $k$ due to a unit prestress force of cable $i, w_{d}$ : dead loads, $A_{k}, A_{k}^{+}, A_{k}^{-}$: total, positive and negative influence area of bending moment at $k$, and $b_{k}^{+}, b_{k}^{-}:$maximum and minimum value of influence line of bending moment at $k$.

The objective function and the constraints of eq. (6) to eq. (10) are summarized as follows.

For the first stage $F\left(P_{i}\right)=-\sum_{i} P_{i} f_{i, t}$

For the second stage $F\left(P_{i}\right)=\sum_{i} P_{i} f_{i, j}$

Constraints :

$$
\begin{aligned}
& \sum_{i} P_{i} f_{i, k}>-w_{d} A_{k}-w_{1} A_{k}^{-}-w_{c} b_{k}^{-}+m_{k}-z_{1} \sigma_{1 c}\left(1+r_{1} N_{k} / A_{g} \sigma_{c}\right) / r_{2} \\
& \sum_{i} P_{i} f_{i, k}<-w_{d} A_{k}-w_{1} A_{k}^{+}-w_{c} b_{k}^{+}-m_{k}+z_{1} \sigma_{1 c}\left(1-r_{1} N_{k} / A_{g} \sigma_{y}\right) / r_{2} \\
& \sum_{i} P_{i} f_{i, k}<-w_{d} A_{k}-w_{1} A_{k}^{+}-w_{c} b_{k}^{+}-m_{k}-z_{u} \sigma_{1 c}\left(1+r_{1} N_{k} / A_{g} \sigma_{c}\right) / r_{2} \\
& \sum_{i} P_{i} t_{i, k}>-w_{d} A_{c k}-w_{1} A_{c k}^{-}-w_{c} t_{\bar{k}}+k_{1} T_{u} \\
& \sum_{i} P_{i} t_{i, k}<-w_{d} A_{c k}-w_{1} A_{c k}^{+}-w_{c} t_{k}^{+}+k_{u} T_{u}
\end{aligned}
$$

where, $A_{c k}, A_{c k}^{+}, A_{c k}^{-}:$total, positive and negative influence area of tensions of cable $k, t_{k}^{+}, t_{k}^{-}$: maximum and minimum value of influence line of cable tensions of cable $k$, and $t_{i, k}$ : tension of cable $k$ due to a unit prestress force of cable $i$.

Since the objective functions and the restraints are all linear functions of cable prestress forces, Linear Programming can be applied. The moment of inertia is then obtained the maximum value from the following equations which correspond eq. (6) to eq. ( 8 ) respectively. The section forces optimised has been used in these equations.

$$
\begin{aligned}
& I_{g_{1}}=\left\{\left(\boldsymbol{M}_{k}^{-}-m_{k}\right) r_{2} / z_{1} \sigma_{1 c}+r_{1} N_{k} / A_{g} \sigma_{c}\right\} I_{g} \ldots \ldots \\
& I_{g 2}=\left\{\left(M_{k}^{+}+m_{k}\right) r_{2} / z_{1} \sigma_{1 c}+r_{1} N_{k} / A_{g} \sigma_{y}\right\} I_{g} \cdots \\
& I_{g 3}=\left\{\left(-M_{k}^{+}-m_{k}\right) r_{2} / z_{u} \sigma_{1 c}+r_{1} N_{k} / A_{g} \sigma_{c} \mid I_{g}\right.
\end{aligned}
$$

where, $I_{g}$ is the assumed moment of inertia. If the girder stiffness obtained by the optimisation with eq. (11) and (12) differs from that assumed, the girder configuration is modified. Then the procedure is continued until convergence. The number of repetition until convergence is only several times, if the initial value is estimated properly. The optimisation has been terminated in most cases when the girder moment of inertia has become uniform along the whole span, which can be reasonably accepted in practical cases. This could be understood by the results described in 5 . The steel girder section has been mainly studied in this paper, whereas, this method can be used for the concrete section or the composite section without any alteration.

\section{GLOBAL BUCKLING STRENGTH OF THE GIRDER}

Large compressive forces are transferred into the girder from cables. It is thought that these forces do not cause a significant effect for few-cable systems, and little research has been carried out on the buckling strength of the girder so far. However, these effects may become considerably larger for multi-cable systems, therefore, the buckling behaviours should be properly considered.

If the girder is considered as a beam on elastic foundation provided by the stays, the simple, explicit $\mathrm{BEF}$ (beam on elastic foundation) solution for elastic critical stress $\sigma_{c r}$ can be taken as an approximation to the elastic buckling of the multi-stay bridges.

$\sigma_{c r}=2 \sqrt{E I_{g} k_{g}} / A_{g}$

with half wave length $l_{c r}$

$$
l_{c r}=\pi\left(E I_{g} / k_{g}\right)^{0.25}
$$


where $E$ is the steel elastic modulus and $k_{g}$ the spring constant of the foundation. $k_{g}$ was calculated by moving a unit load on each point of the bridge model.

The practical limiting value of the axial force, taking account of yielding and/or local instabilities, including the effect of imperfections, can then be inferred by postulating an appropriate strut curve. For the present purpose of rational comparative design, it has been felt sufficient to use the very simple, and generally conservative Rankine strut interaction formula.

$$
\frac{1}{\sigma_{c}}=\frac{1}{\sigma_{c r}}+\frac{1}{\sigma_{y}}
$$

The spring constant is maximum at the tower and decreases towards the centre on the main span and the centre on the side span as well. $\sigma_{c}$ is proportional to the square root of $k_{g}$, therefore, has the same tendency. The axial compressive force is maximum at the tower and decreases towards the centre and the abutment as well, but drop more sharply. Therefore, the critical buckling section seems to exist near the quarter point on the main span.

Nakai's proposal ${ }^{8)}$ has been adopted to take the shear lag effect into consideration. He assumed a parabolic curve with fourth order for normal stress distribution. It is difficult to fix the equivalent span by finding two points with zero bending moment, which is the recommended method in BS 5400 , due to the complex moment diagram. Nakai has introduced the concept of additional moments due to the shear lag effect instead of the equivalent length.

\section{SCOPE AND RESULTS OF A PARAMETRIC STUDY}

In this study the carriageway is assumed to be a two lane dual carriageway requiring a deck width of $22 \mathrm{~m}$. A three-span fan-shaped configuration with equal side spans and continuous stiffening girder is assumed. Examples have been evaluated for main span of $250 \mathrm{~m}$ and $450 \mathrm{~m}$, with three values of the side span length against the main span length (namely $0.3,0.4,0.45$ ), and cable systems with 3 and 12 stays
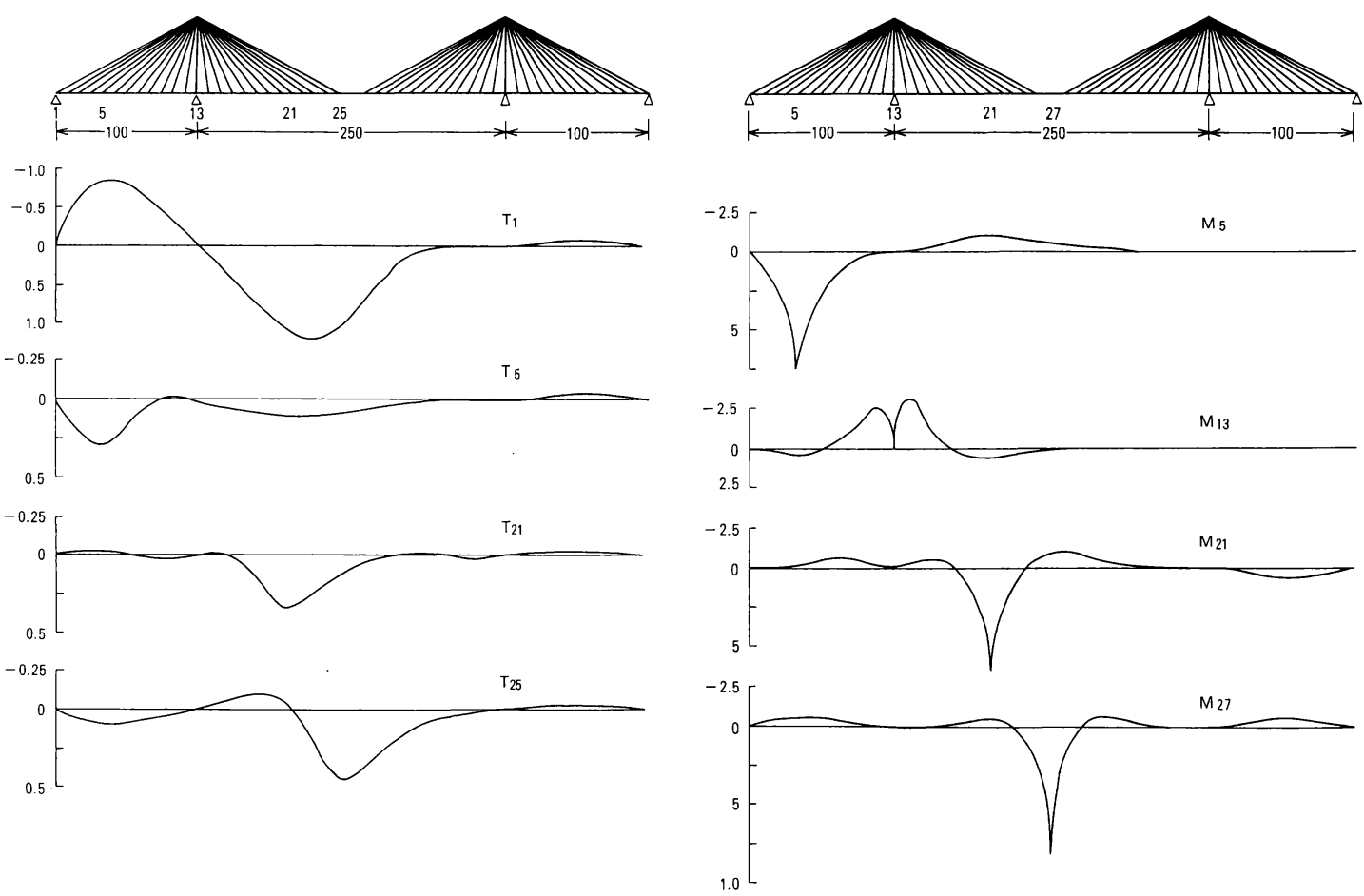

Fig. 3 Influence lines of stay tensions.

Fig. 4 Influence lines of girder moments. 
per fan. The height of towers has been taken as the main span / 6 for the three-cable system and the main span / 4.5 for the twelve-cable systems. Dead loads consist of the steel work weight and superimposed dead loads, principally representing the surfacing. Spiral strands with the ultimate strength of 1500 $\mathrm{N} / \mathrm{mm}^{2}$ and the elastic modulus of $150 \mathrm{kN} / \mathrm{mm}^{2}$ have been taken as stays. Steel grade $50 \mathrm{C}$ of the British standard with $\sigma_{y}=345 \mathrm{~N} / \mathrm{mm}^{2}$ and the elastic modulus of $205 \mathrm{kN} / \mathrm{mm}^{2}$ is used as steel plates. The minimum and maximum plate thicknesses were set at $12 \mathrm{~mm}$ and $40 \mathrm{~mm}$ respectively from a viewpoint of practical fabrication.

Fig. 3 and 4 show the typical influence lines of cable tensions and girder moments. Those of bending moments of multi-cable system have sharper peaks than the few-cable system indicating a short governing loaded length and thus a more severe live loads.

Fig. 5 is a typical optimisation result. (a) shows the maximum and minimum bending moment envelopes before and after cables have been prestressed. It is clearly shown that, due to prestressing, the hogging moments at the tower drop sharply, the sagging moments at the centre rise, and there are no large changes at other points. The ranges between maximum and minimum bending moments at a given position do not
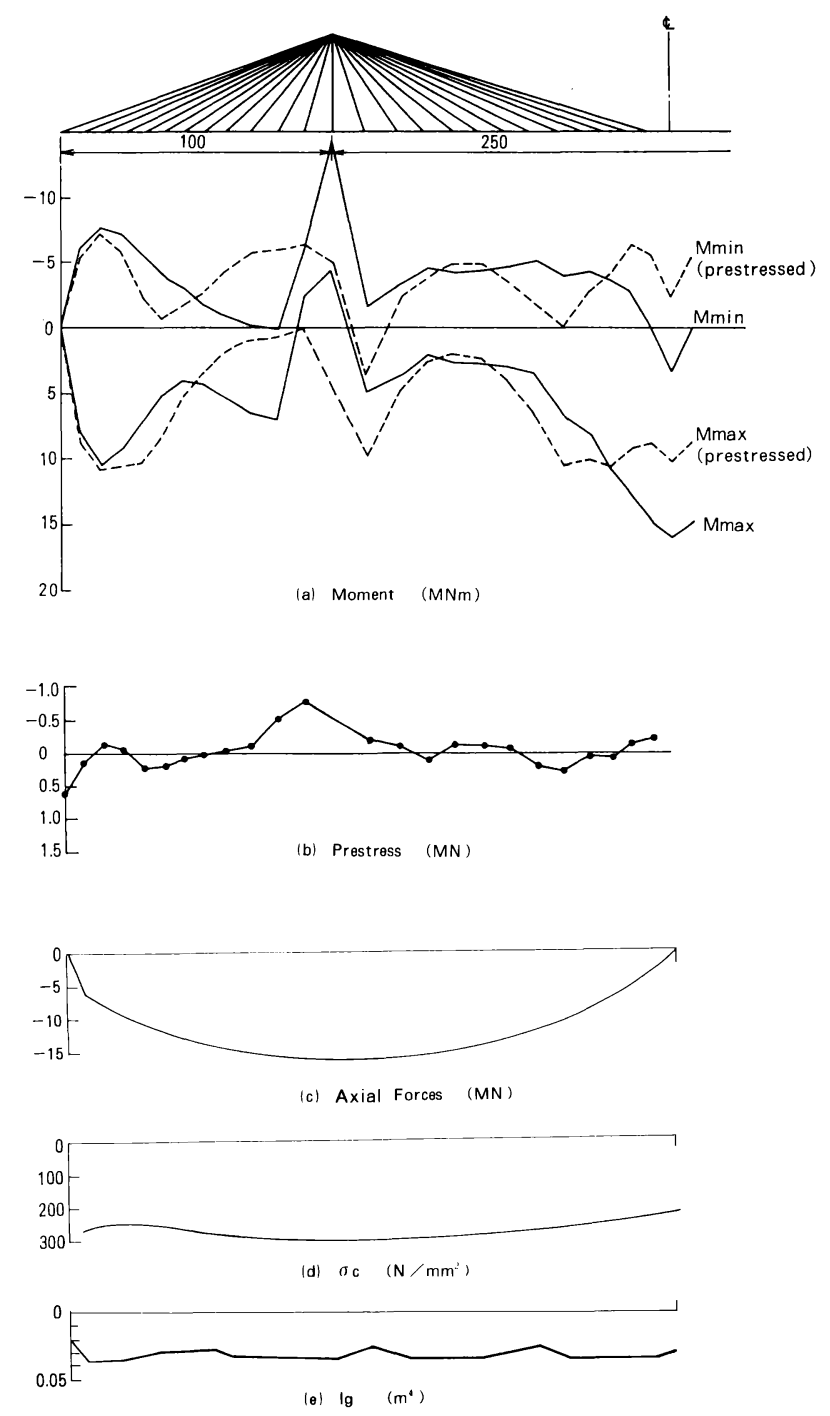

Fig. 5 Moment diagram computed by the optimisation program. 
change, and the maximum ranges exist near the abutment or mid-centre, which set a limit of opimisation of girder stiffnesses. (b) shows the prestress forces to be introduced for each cable. The prestresses near the tower are large to reduce the moment at those points. Those of anchor stays are also significantly large. (c) is the axial forces of the girder, which is maximum at the tower and decreases towards the centre and the abutment. (d) is the global buckling capacity which have been calculated by eq. (27) and ranges between $200 \mathrm{~N} / \mathrm{mm}^{2}$ and $300 \mathrm{~N} / \mathrm{mm}^{2}$. (e) shows the moment of inertia of the girder obtained by the optimisation.

Table 1 is a summary of section forces and girder stiffnesses for all bridge configurations compared in this study. The girder depth has been chosen by several trials so that it produces the minimum stiffness. These results were all obtained by the first objective function of eq. (11) and converged quickly. Although the second objective function of eq. (12) was required in some extreme cases which were not stated in this paper, convergence was not always satisfactory. The influence of the various factors on girder selection is typified by the following example.

Take the bridge with $L=250 \mathrm{~m}, L_{1} / L=0.4$ and twelve stays per fan. The moment influence lines shown in Fig. 4 shows that, for sagging moment at the tower, the loaded length is $95 \mathrm{~m}$, giving a live loads of $52.2 \mathrm{kN} / \mathrm{m}$. The total hogging moment due to live loads and dead loads, including additional moments due to shear lag, is $14.25 \mathrm{MNm}$ which is reduced to $4.89 \mathrm{MNm}$ by cable prestressing. The axial force is 16. $34 \mathrm{MN}$. From the stress check of BS 5400 the moment of inertia is decided as $0.0352 \mathrm{~m}^{4}$.

At the centre of the bridge the loaded length for sagging moment is $60 \mathrm{~m}$, giving live loads of $64.8 \mathrm{kN} / \mathrm{m}$. The total sagging moment is $16.00 \mathrm{MNm}$ which is reduced to $10.41 \mathrm{MNm}$ by optimisation. The axial force is zero and the girder stiffness obtained is $0.0318 \mathrm{~m}^{4}$.

It is understood from Table 1 that the girders with 12 stays per fan is much more slender than that with 3 cables, and the girder stiffness with shorter side spans is a little smaller than that with longer side spans. The web height of the girder with 12 stays can become as low as $1.0 \mathrm{~m}$ for $250 \mathrm{~m}$ main span and $1.5 \mathrm{~m}$ for the $450 \mathrm{~m}$ main span. In practical cases, the one box girder section assumed in this study may had better be modified to multi-box or multi I-section girders for such very low web height girders. It should be reminded, of course, that the aero-dynamic stability of those sections must be checked carefully.

The moment of inertia obtained by this optimisation method is almost uniform over the whole span. A uniform section girder is of great merit for manufacturing. It is noted that the girder stiffness obtained is

Table 1 The optimised results of section forces and girder stiffnesses

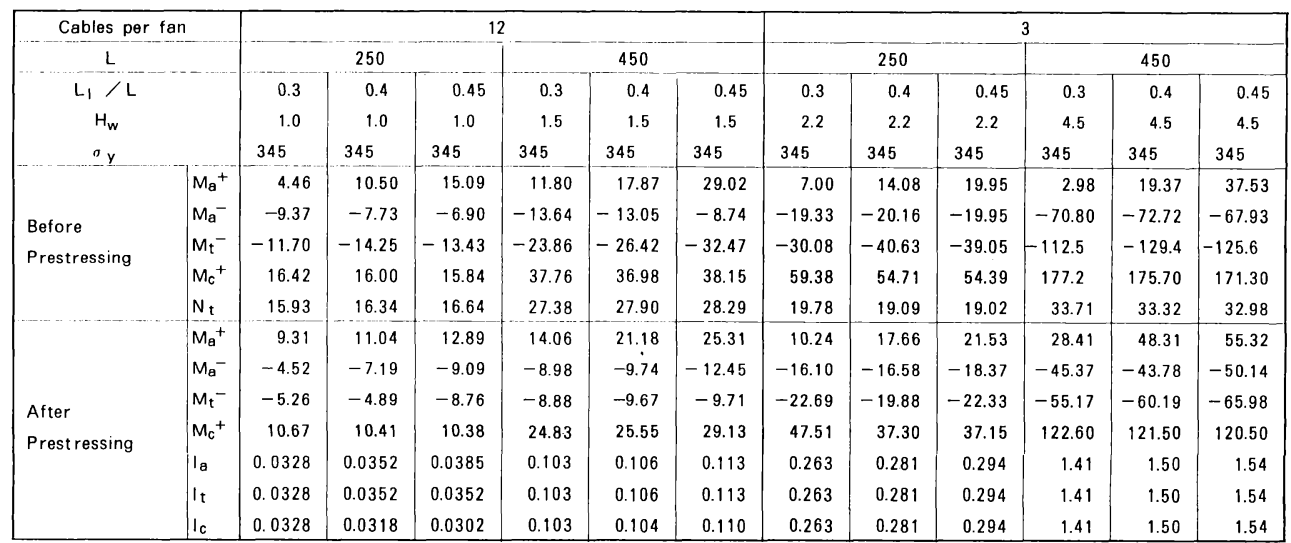

$\mathrm{Ma}, \mathrm{Mt}$ and $\mathrm{Mc}$ : bending moments at $a, t$ and $c(M N . m)$

$\mathrm{Nt}$ : compressive axial force at $t(\mathrm{MN})$

$\mathrm{la}, \mathrm{It}$ and $\mathrm{Ic}$ : moment of inertia at $a, t$ and $c\left(\mathrm{~m}^{4}\right)$

+ and - : maximum and minimum

$\mathrm{L}$ : main span $(\mathrm{m})$

$L_{1}:$ side span $(m)$

$H_{w}$ : web height $(m)$

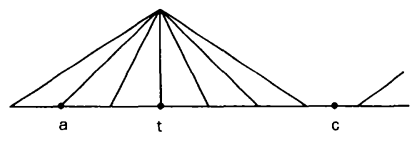


much smaller than that of the existing bridges, although more recent designs for multi-stayed bridges, such as the Annacis Bridge, have approached the corresopnding reductions. The effect of the limit states design method compared with the allowable design method would be about $10 \%$ or $15 \%$, judging from the consideration in 2., therefore, a large reduction of girder stiffness was obtained mainly by the cable prestress optimisation.

\section{CONCLUSION}

Cable-stayed bridges with multi-cables and few-cables have been consistently optimised using the limit states design. It has been concluded from the foregoing results and discussions:

(1) Limit states design has been applied to cable-stayed bridges. The longer the bridge span extends, the larger becomes the rate of the dead loads against the total weight, indicating that the structural safety factor could be more accurately estimated and long span bridges could be constructed more economically than they would be designed by the allowable stress method.

(2) The optimisation method has been developed to minimise the girder stiffness by introducing proper cable prestresses. The girder stiffness obtained is almost uniform along the whole span.

(3) Girder stiffness of the multi-cable system can be substantially smaller than that of the few-cable system. The reduction may be a factor of 8 for the $250 \mathrm{~m}$ span, and a factor of 14 for the $450 \mathrm{~m}$ span.

(4) Girder stiffness required with a short side span is slightly smaller than with a longer side span.

(5) The range between the maximum and minimum bending moments at a given position on the girder is largest at the centre on the main span or near the abutment on the side span. These bending moment ranges set the limit of the optimisation of the girder stiffness.

(6) Although it is possible to design the girder very flexible by a static analysis, the shape and type of the girder must be carefully investigated aero-dynamically.

(7) Compressive axial forces near the middle supports are generally very large especially for the multi-cable system, and are a dominant factor to decide the girder stiffness. The buckling capacity of the girder has been estimated based on the BEF solution, which has been satisfactory for this kind of comparative study. However, the buckling analysis by FEM may be useful to validate this method or tackle more complicated features, such as the effect of residual stresses or a bridge camber. In order to construct the bridge with much longer span, the erection and design methods should be developed to reduce these compressive forces.

Cable prestressing has been proved effective in reducing the required girder bending strength. However, the report on the Nagoya Harvour West Bridge ${ }^{9)}$ pointed out that the cable adjustment during erection was quite difficult and prestressing was sometimes accompanied by a significant error. Therefore, the construction errors should be properly and systematically considered in design, in addition the cable force adjustment method should be developed to improve the erection reliability.

Finally it is reminded that the results obtained in this paper have been used in our paper ${ }^{10)}$ on the fatigue problem of stays on cable-stayed bridges.

\section{REFERENCES}

1) The design of steel bridge structures, Civil Engineering, Steel Supplement, pp. 6 11, November, 1985.

2) Haaijer G. et al. : Autostress design of steel bridges, Journal of Structural Engineering, ASCE, Vol. 109, No. 1, pp. 188 199, 1983.

3) Shinohara Y. et al. : A study on the design load for the Akashi Bridge, Chap. 4, Report on design and construction of the Honshu-Shikoku Bridges (in Japanese), No.2357, Report of Public Work Research Centre, 1986.

4) British Standards Institution : BS 5 400, Part 1,2,3 Steel, concrete and composite bridges, 1978 and 1982.

5) Nagai M. et al. : A study on the determination of the basic configuration of the three span continuous cable-stayed bridges with multiple cables (in Japanese), Proc. of JSCE, pp. 343 352, No. 10, Vol. 362, 1985.

6) Yamada Y. et al. : Studies on optimisation of cable prestresses of cable-stayed bridges (in Japanese), Proc. of JSCE, pp. 415 423, No. 4, Vol. 356, 1985. 
7) Hoshino M. : A method to determine cable prestresses of cable-stayed bridges (in Japanese), Proc. of JSCE, pp. 487 494, No. 10, Vol. 374, 1986 .

8) Nakai $H$. et al. : A flexual normal stress analysis in cable-stayed bridges with multi-cell box girder considering shear lag phenomenom, Proc. of JSCE, Structural Engineering / Earthquake Engineering, pp. 131 140, Vol. 2, No. 1, 1985.

9) Nonaka K. and Kawahito T. : The construction report on the Nagoya Harvour West Bridge (in Japanese), Bridge and Foundation Journal, pp. 22 30, No. 5, Vol. 19, 1985.

10) Wyatt T.A. and Nakamura S. : On the cable-fatigue sensitivity of multi-stayed bridges, International Conference on Cable-stayed Bridges, Bangkok, November 1987.

(Received December 23 1987) 